\title{
The Response of an Idealized Ocean Basin to Variable Buoyancy Forcing
}

\author{
M. A. LuCAS AND J. J. Hirschi \\ School of Ocean and Earth Science, Southampton Oceanography Centre, University of Southampton, Southampton, United Kingdom \\ J. D. STARK \\ Met Office, Exeter, Devon, United Kingdom \\ J. MAROTZKE \\ Max-Planck-Institut für Meteorologie, Hamburg, Germany
}

(Manuscript received 23 February 2004, in final form 4 October 2004)

\begin{abstract}
The response of an idealized ocean basin to variable buoyancy forcing is examined. A general circulation model that employs a Gent-McWilliams mixing parameterization is forced by a zonally constant restoring surface temperature profile, which varies with latitude and time over a period $P$. In each experiment, 17 different values of $P$ are studied, ranging from 6 months to $32000 \mathrm{yr}$. The model's meridional overturning circulation (MOC) exhibits a very strong response on all time scales greater than $15 \mathrm{yr}$, up to and including the longest forcing time scales examined. The peak-to-peak values of the MOC oscillations reach up to $125 \%$ of the steady-state maximum MOC and exhibit resonance-like behavior, with a maximum at centennial to millennial forcing periods (depending on the vertical diffusivity). This resonance-like behavior stems from the existence of two adjustment time scales, one of which is set by the vertical diffusion and the other of which is set by the basin width. Furthermore, the linearity of the response as well as its lag with the forcing varies with the forcing period. The considerable deviation from the quasi-equilibrium response at all time scales above $15 \mathrm{yr}$ is surprising and suggests a potentially important role of the ocean circulation for climate, even at Milankovich time scales.
\end{abstract}

\section{Introduction}

The response of the meridional overturning circulation (MOC) to pure buoyancy forcing has been the subject of relatively few studies. Those that exist have concentrated on the scaling behavior between the equator-to-pole temperature gradient $(\Delta T)$ and the strength of the maximum overturning (Zhang et al. 1998; Huang 1999), based on the work of Bryan and Cox (1967), whose principal aim, however, had been to develop a scaling relationship between horizontal currents and the vertical diffusivity. Deriving the scaling law that links the MOC to the north-south surface temperature gradient implies that the meridional temperature gradient is proportional to the zonal temperature gradient. Marotzke (1997) presented theoretical arguments that this proportionality did indeed exist, and his conclusions were supported by the numerical results of Park

Corresponding author address: Marc Lucas, School of Ocean and Earth Sciences, Southampton Oceanography Centre, European Way, Southampton SO14 3ZH, United Kingdom.

E-mail:mall@soc.soton.ac.uk and Bryan (2000). However, Scott (2000) cast doubt upon the robustness of the scaling law: his results suggest that the scaling law varies with latitudes and that it fails to capture the geographical displacement of the overturning cell as $\Delta T$ varies. He did not, however, study in detail the structure of the circulation or how it is affected by changes in $\Delta T$. Park and Bryan (2001) also looked at the effect of different vertical coordinate systems on a purely buoyancy-forced ocean basin.

In contrast to these relatively few studies, there have been many model studies that investigated MOC variability on the interdecadal time scale, in pure ocean models with constant forcing (e.g., Marotzke 1990; Weaver and Sarachik 1991; Weaver et al. 1993; Winton 1996; Greatbatch and Peterson 1996; te Raa and Dijkstra 2002), in coupled ocean-atmosphere models (e.g., Delworth et al. 1993; Delworth and Greatbatch 2000; Delworth and Mann 2000), and in response to North Atlantic Oscillation (NAO)-style forcing (Visbeck et al. 1998; Hurrell et al. 2001). Theoretical arguments for the emergence of MOC variability have been put forward by Colin de Verdiere and Huck (1999), te Raa and Dijkstra (2002), and Eden and Greatbatch (2003). 
There have also been efforts to study the oceanic response to Milankovitch orbital forcing. Brickman et al. (1999) conducted a study using a 2.5D atmosphereocean model run for $3.2 \times 10^{6} \mathrm{yr}$. They found that the strongest response was in the obliquity band and that the response in the eccentricity band was suppressed. Their explanation for this was that the main effect of obliquity was to control the seasonal contrast and, because deep-water formation happens in winter, the harsher the winter is, the greater is the amount of deep water formed and the stronger the overturning is. Their results also showed that in the obliquity band the global ocean average temperatures were negatively correlated with the atmospheric ones because of a rectifying effect by the ocean.

The present paper addresses a gap in all previous works in that it investigates the effect of pure variable buoyancy forcing on the MOC under three-dimensional dynamics. We use very idealized forcing, which varies sinusoidally in time, and tune through a wide range of periods, following the strategy sketched in Visbeck et al. (1998).

In section 2 of this paper, we describe the model and the experimental setup. Section 3 gives a descriptive account of the main results. An in-depth analysis and discussion are successively provided in sections 4 and 5 , addressing the effects of diffusion and the influence of the basin width, respectively. Section 6 compares boundary current velocities and the meridional overturning, and section 7 briefly presents conclusions.

\section{Model description and experimental setup}

\section{a. Model description}

The model used is a parallelized version of the Geophysical Fluid Dynamics Laboratory Modular Ocean Model, which can distribute the various processes on an array of processors (Webb 1996). The free-surface numerics have been updated by including the free-surface numerical code of the Ocean Circulation and Climate Advanced Modelling Project (Webb 1995). The model also includes the eddy parameterization scheme of Gent and McWilliams (1990) as implemented by Griffies (1998).

The domain is a $60^{\circ}$-wide basin with solid boundaries and 15 levels in the vertical direction, extending from the equator to $60^{\circ} \mathrm{N}$. The horizontal resolution is $4^{\circ} \times$ $4^{\circ}$. Table 1 lists the default parameters.

In the initial conditions, the salinity is set to $35 \mathrm{psu}$ throughout the model and the salinity fluxes are set to zero. The wind effect is removed by setting all the surface wind stresses to zero. The temperature fields are initialized by setting the surface temperature to $20^{\circ} \mathrm{C}$ at all latitudes and longitudes and decreasing it by $1^{\circ}$ at each level. Thus, the coldest temperature is at the bottom and is $5^{\circ} \mathrm{C}$.

The temperature is forced using a Newtonian relax-
TABLE 1. Summary of numerical parameters.

\begin{tabular}{ll}
\hline \hline \multicolumn{1}{c}{ Parameter } & \multicolumn{1}{c}{ Value } \\
\hline Basin width, length & $60^{\circ}, 60^{\circ}$ \\
Basin depth & $5000 \mathrm{~m}$ \\
No. of vertical levels & 15 \\
Lon, lat grid spacing & $4^{\circ}, 4^{\circ}$ \\
Vertical, horizontal diffusion & $1 \times 10^{-4} \mathrm{~m}^{2} \mathrm{~s}$ \\
$\quad$ coefficient & \\
Isopycnal thickness diffusivity & $2 \times 10^{3} \mathrm{~m}^{2} \mathrm{~s} \mathrm{~s}^{-1}$ \\
Lateral eddy diffusivity, viscosity & $1 \times 10^{5} \mathrm{~m}^{2} \mathrm{~s}^{-1}, 2 \times 10^{3} \mathrm{~s}$ \\
Isopycnal tracer diffusivity & $2 \times 10^{7} \mathrm{~cm}^{2} \mathrm{~s}^{-1}$ \\
Temperature restoring time scale & $40 \mathrm{days}^{-1}$ \\
Momentum time step & $14400 \mathrm{~s}$ \\
Tracer time step & $150000 \mathrm{~s}$ \\
\hline
\end{tabular}

ation scheme in which the restoring period is set to 40 days. In the initial spinup, the sea surface temperature is restored using a zonally uniform cosine function with a peak-to-peak amplitude of $26^{\circ} \mathrm{C}$ and a value at the equator of $28^{\circ} \mathrm{C}$. The spinup lasts 8000 model years, until the value of the maximum MOC becomes virtually constant.

\section{b. Experimental strategy}

In the time-varying experiments, a sinusoidal restoring temperature profile is used. It varies with latitude and time according to

$$
T(\Phi, t)=[13+\cos (2 \pi t / P)][\cos (3 \Phi)-1]+28,
$$

where $T$ is the restoring temperature, $\Phi$ is latitude, $t$ is time, and $P$ is the forcing period (Fig. 1). As a result, the north-south temperature gradient is modified by varying the northernmost temperature, not the equatorial temperature, as was done previously (Scott 2000). In our experiments, we vary the SST at $60^{\circ} \mathrm{N}$ by $4^{\circ} \mathrm{C}$, giving us a $4^{\circ} \mathrm{C}$ variation in the meridional temperature contrast. As is shown in Fig. 2, taken from the National Centers for Environmental Prediction (NCEP) reanalysis (Kalnay et al. 1996), such a variation is smaller than today's seasonal range. However, because we propose to examine the effect of very long period oscillations, we need to have an idea of the past amplitudes in SST.

By analyzing the $\delta^{18} \mathrm{O}$ isotope records from various sites in the North Atlantic Ocean for the last $1.1 \times 10^{6}$ yr, Ruddiman et al. (1986) concluded that maximum SST variations at about $60^{\circ} \mathrm{N}$ were in excess of $10^{\circ} \mathrm{C}$ for summer and winter temperatures. This estimate was also obtained by the Climatic Extremes (CLIMEX) project in their world maps of the last two climatic extremes: 18000 years ago, the last glacial maximum, and 8000 years ago, the Holocene optimum (CGCM 1999). These studies show that the $4^{\circ} \mathrm{C}$ range we use is modest in comparison with the range of naturally occurring values.

Six different experiments are done with different values for the vertical diffusion coefficient and varying topography and basin width, as well as one run that 
A

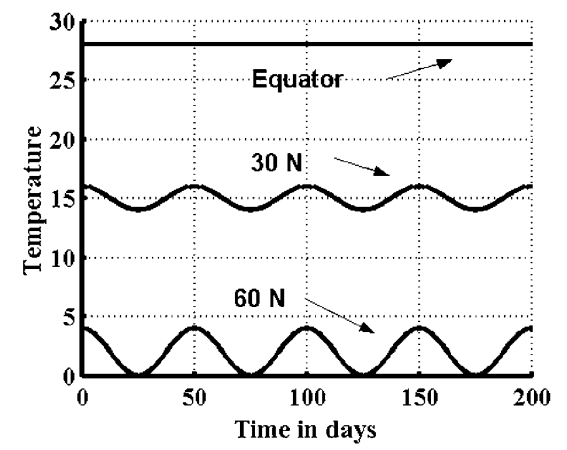

B

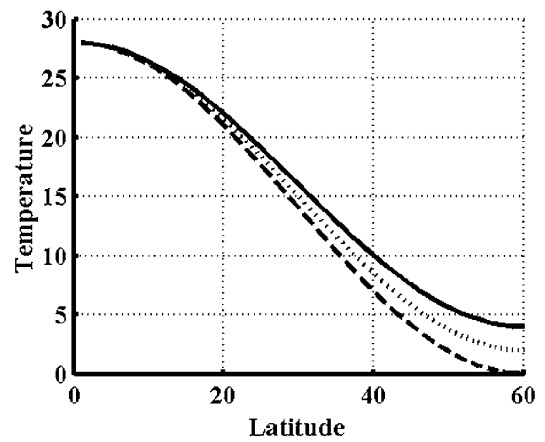

FIG. 1. Summary of variable forcing setup: (left) the evolution of the restoring temperature at three latitudes for a forcing period of 50 days; (right) the maximum (solid line) and the minimum (dashed line) forcing profile, as well as the forcing profile used to spin up the model (dotted line).

includes winds. Furthermore, a run with fixed fluxes is also made. Table 2 provides a brief description of each of the experiments.

During the runs of the restoring experiments-R1, R2, R5, T1, D1, and W1-the forcing period $P$ is gradually increased from 6 month to 32000 yr. For each value of $P$, the model is run until a cyclostationary state has been reached. Table 3 lists the actual periods used.

\section{c. Asymptotic forcing}

The constant restoring profiles of $28^{\circ}$ to $0^{\circ} \mathrm{C}$ and $28^{\circ}$ to $4^{\circ} \mathrm{C}$ can be seen to correspond to a time-varying profile of infinite period because they represent an infinitely slow change in the forcing. They can therefore be deemed to represent the asymptotic behavior of the system.

Both experiments are started from the end of the spinup and are run for $4000 \mathrm{yr}$. Once equilibrium is

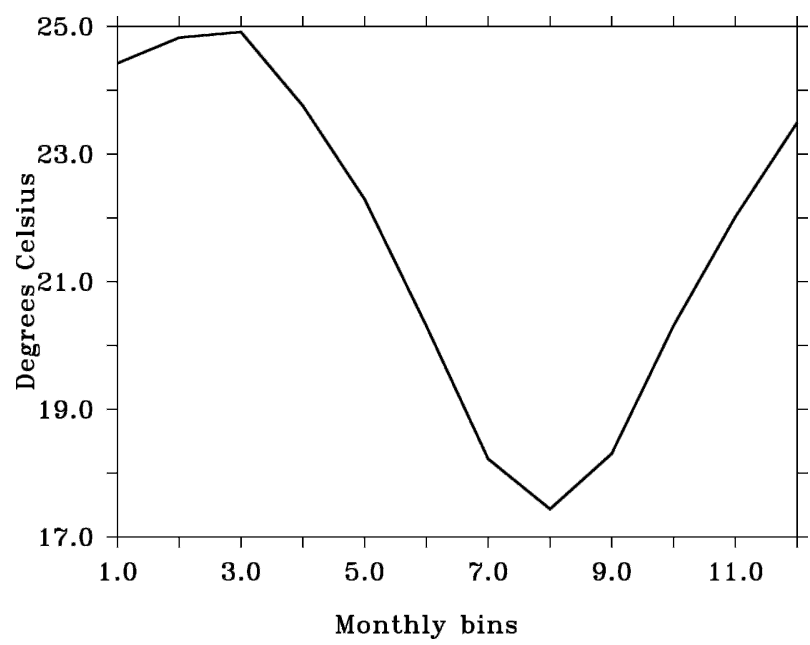

FIG. 2. Monthly temperature gradient between the equator and $60^{\circ} \mathrm{N}$ in the Atlantic, obtained from NCEP data for the last $50 \mathrm{yr}$. reached, the maximum overturning takes the value of 12.16 and $11.76 \mathrm{~Sv}\left(1 \mathrm{~Sv} \equiv 10^{6} \mathrm{~m}^{3} \mathrm{~s}^{-1}\right)$, respectively. This increase in the strength of the overturning when the meridional density contrast decreases is surprising. An in-depth analysis of this behavior is beyond the scope of this paper. However, it can be said that it occurs for a different reason from the one in Nilsson and Walin (2001) and Nilsson et al. (2003), because here vertical diffusivity is prescribed.

The asymptotic forcing experiments show that the $4^{\circ} \mathrm{C}$ change in temperature between the two asymptotic experiments only leads to a $0.4-\mathrm{Sv}$ change in the value of the maximum overturning. Therefore, any change in the overturning observed during the variable forcing beyond 0.4 Sv must be attributed to the oscillatory nature of the forcing.

\section{Variable forcing}

\section{a. Overturning}

Figure 3 a shows the behavior of the maximum overturning for R1. The system is profoundly affected by the oscillations in the forcing, even for a forcing period of $32000 \mathrm{yr}$, which is within the Milankovitch cycle time band. The average maximum overturning value for each of the forcing periods is greater than the value of

TABLE 2. Summary of experiments.

\begin{tabular}{lccl}
\hline \hline Expt & $\begin{array}{c}\text { Vertical } \\
\text { diffusion } \\
\left(\mathrm{cm}^{2} \mathrm{~s}^{-1}\right)\end{array}$ & $\begin{array}{c}\text { Basin } \\
\text { width }\end{array}$ & \multicolumn{1}{c}{ Note } \\
\hline R1 & 1 & $60^{\circ}$ & \\
R2 & 2 & $60^{\circ}$ & \\
R5 & 5 & $60^{\circ}$ & \\
T1 & 1 & $60^{\circ}$ & Midocean topography \\
D1 & 1 & $60^{\circ}$ & Winds included \\
W1 & 1 & $120^{\circ}$ & Wide basin \\
F1 & 1 & $60^{\circ}$ & Constant fluxes \\
\hline
\end{tabular}


TABLE 3. List of forcing period-integration time pairs (yr) used in the experiments.

\begin{tabular}{ccrr}
\hline \hline $\begin{array}{c}\text { Forcing } \\
\text { period }\end{array}$ & $\begin{array}{c}\text { Integration } \\
\text { time }\end{array}$ & $\begin{array}{c}\text { Forcing } \\
\text { period }\end{array}$ & $\begin{array}{c}\text { Integration } \\
\text { time }\end{array}$ \\
\hline 0.5 & 4000 & 250 & 4000 \\
1 & 4000 & 500 & 6000 \\
2 & 4000 & 1000 & 10000 \\
4 & 4000 & 2000 & 12000 \\
8 & 4000 & 4000 & 20000 \\
15 & 4000 & 8000 & 48000 \\
30 & 4000 & 16000 & 80000 \\
60 & 4000 & 32000 & 96000 \\
120 & 4000 & & \\
\hline
\end{tabular}

the maximum overturning during the spinup, which corresponds to the average forcing. The location of the maximum overturning is also very regular for each forcing period. For the maximum values, it is situated at about $53^{\circ} \mathrm{N}$ and at about 2000-m depth. As it decreases, it shoals and shifts southward, to about $40^{\circ} \mathrm{N}$.

The maximum overturning curves also display a maximum range, which occurs for a period of $2000 \mathrm{yr}$. At a forcing period of $30 \mathrm{yr}$, the overturning reaches its absolute minimum value. From then on, the minimum value of the maximum overturning will continuously increase, even as the maximum eventually starts to decrease. The other notable feature is the presence of a significant increase in the amplitude when the forcing switches from a period of $8 \mathrm{yr}$ to a period of $5 \mathrm{yr}$. This feature is clearly visible in Fig. 3b, which zooms in on the transition between a forcing period of $8 \mathrm{yr}$ and a forcing period of $15 \mathrm{yr}$ shown in Fig. 3a.

The following experiments are used to test the sen-
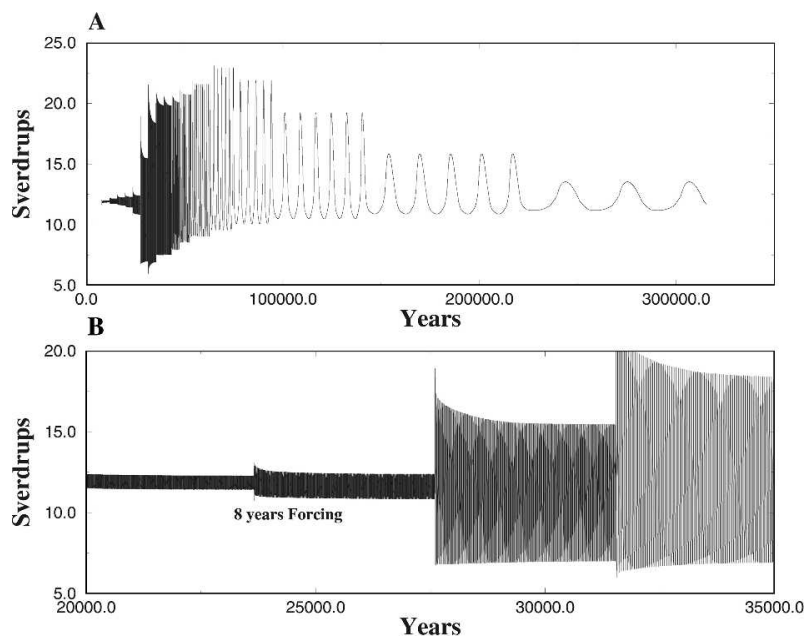

FIG. 3. (a) Maximum overturning against time for expt R1. Vertical diffusivity is $1 \mathrm{~cm}^{2} \mathrm{~s}^{-1}$. The model is run for 17 forcing periods and for each until a cyclostationary state has been achieved. (b) Maximum overturning against time in experiment R1 for four successive forcing periods: $4,8,15$, and $30 \mathrm{yr}$. This panel highlights the jump in amplitude in the overturning as the period increases from 8 to $15 \mathrm{yr}$. sitivity of the system to vertical diffusivity and topography. Experiments R2 and R5 are identical to R1 except that the vertical diffusivity is set to 2 and $5 \mathrm{~cm}^{2} \mathrm{~s}^{-1}$, respectively. The results for the overturning are shown in Fig. 4. In general, the values for the overturning are higher than for R1 and are higher for R5 than for R2. This result is consistent with experiments of constant forcing (e.g., Bryan 1987; Colin de Verdiere 1988; Park and Bryan 2000). In both cases, the maximum amplitude in the overturning occurs for a period smaller than in R1. For R2, the maximum amplitude occurs for a forcing period of $60 \mathrm{yr}$; for R5, it occurs for a forcing period of $30 \mathrm{yr}$. As in R1, there is also a considerable jump from a forcing period of $8 \mathrm{yr}$ to a forcing period of $15 \mathrm{yr}$. Increasing the diffusivity shifts the maximum amplitude in the overturning toward the smaller periods. It does not, however, affect the jump in the amplitude of the maximum overturning that occurs between the 8-yr forcing period and the 15 -yr forcing period.

Experiment T1 is identical to R1 except for the introduction of an idealized north-south midbasin ridge that is $2500 \mathrm{~m}$ high and 4 cells wide. The result for the overturning is shown in Fig. 5. In general, the overturning is slightly weaker than in experiment R1. Furthermore, the maximum amplitude in the overturning occurs for a forcing period of $120 \mathrm{yr}$. The jump between the forcing period of $8 \mathrm{yr}$ and the forcing period of $15 \mathrm{yr}$ observed in all of the other experiments is still present. However, the absolute minimum is no longer so close to the jump in amplitude because it occurs for a period of $120 \mathrm{yr}$.

Last, Fig. 6b shows the results for the overturning streamfunction in D1, which has an identical setup to $\mathrm{R} 1$ except that an idealized wind forcing is applied. The
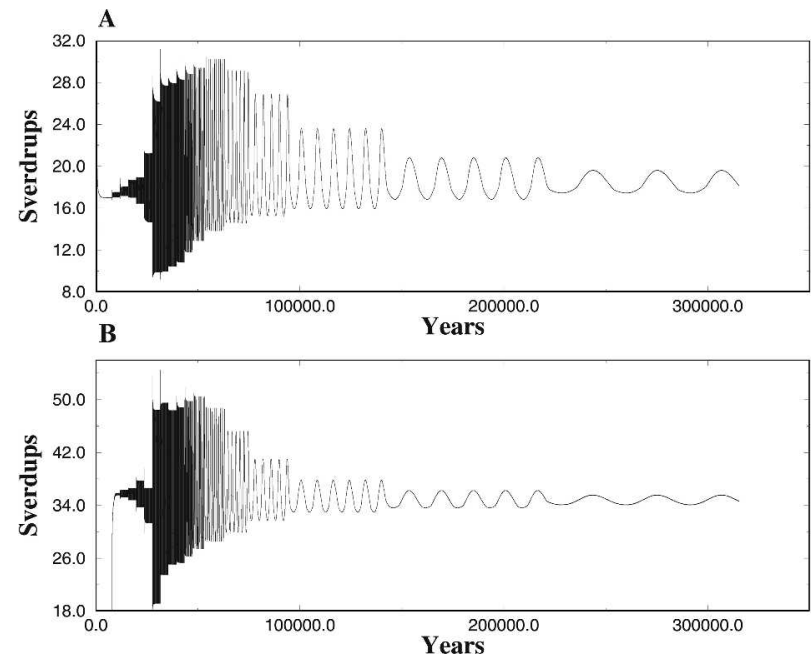

FIG. 4. (a) Maximum overturning against time for expt R2. The diffusion is $2 \mathrm{~cm}^{2} \mathrm{~s}^{-1}$. The model is run for 17 forcing periods and for each until a cyclostationary state has been achieved. (b) Maximum overturning against time for expt R5. The diffusion is 5 $\mathrm{cm}^{2} \mathrm{~s}^{-1}$. The model is run for 17 forcing periods and for each until a cyclostationary state has been achieved. 


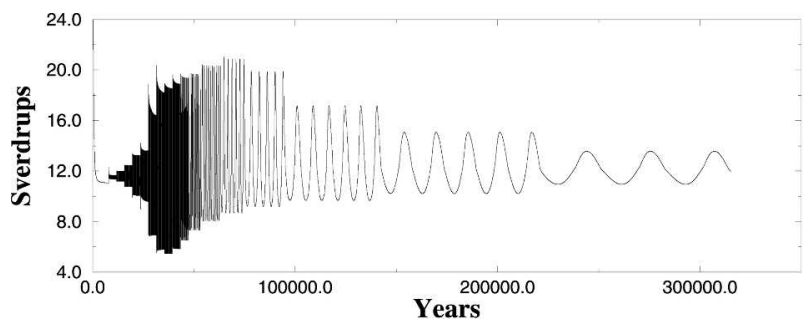

FIG. 5. Maximum overturning against time for expt T1. The diffusion is $1 \mathrm{~cm}^{2} \mathrm{~s}^{-1}$. The basin topography includes a northsouth ridge $2500 \mathrm{~m}$ high. The model is run for 17 forcing periods and for each until a cyclostationary state has been achieved.

actual wind stress values used are those of Weaver and Sarachik (1990) and are shown in Fig. 6a. In general, the wind decreases the strength of the overturning. Most of this decrease is accounted for in a reduction of the strength of the western boundary current (not shown). Furthermore, the reduction in the strength of the western boundary current means that less warm water will be advected northward. As a result, at all times during a forcing cycle, the deep water formed is slightly colder than for a run without winds (not shown). This effect in turn increases the stratification slightly and decreases the strength of the convection, the consequence of which is that the overturning is generally weaker throughout a forcing cycle for D1 relative to R1.

The maximum amplitude is now of $10.6 \mathrm{~Sv}$ and occurs for a forcing period of $2000 \mathrm{yr}$. Once again, the jump occurs between the forcing periods of 8 and $15 \mathrm{yr}$. As for R1, the absolute minimum is reached for a forcing period of $30 \mathrm{yr}$.

Two robust and distinct features occur in all of the experiments: a maximum amplitude in the overturning and a considerable jump in the amplitude between the forcing period of $8 \mathrm{yr}$ and that of $15 \mathrm{yr}$. To understand what brings about these features, we will hereinafter focus on experiment R1.

\section{b. Bottom temperature}

Figure 7 is a plot of the forcing temperature at $60^{\circ} \mathrm{N}$ - that is, the temperature to which the latitude of $60^{\circ}$ is restored-and the minimum bottom temperature in R1. The bottom temperature displays some regular oscillations for all forcing periods. These oscillations have a very small amplitude for the forcing periods of 8 and $250 \mathrm{yr}$, clearly showing that very little of the oscillatory behavior of the forcing reaches the deep ocean. Changing the forcing period does have an effect in that the mean value of the temperature in the deep ocean is lowered as the period is increased. This result is partly because the greater the forcing period is, the colder the minimum temperature found in the surface ocean during a cycle becomes (because the vertical diffusivity becomes increasingly efficient in capturing the forcing signal as the forcing period becomes longer). It is this
A

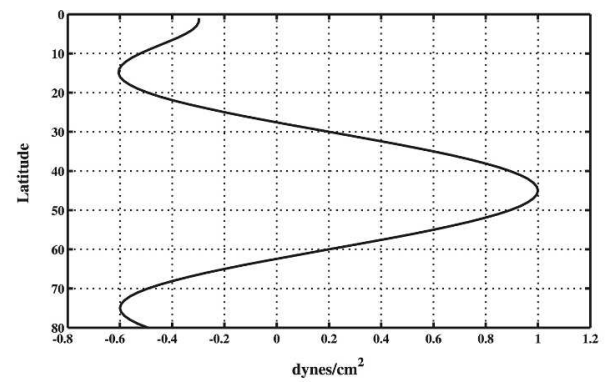

B

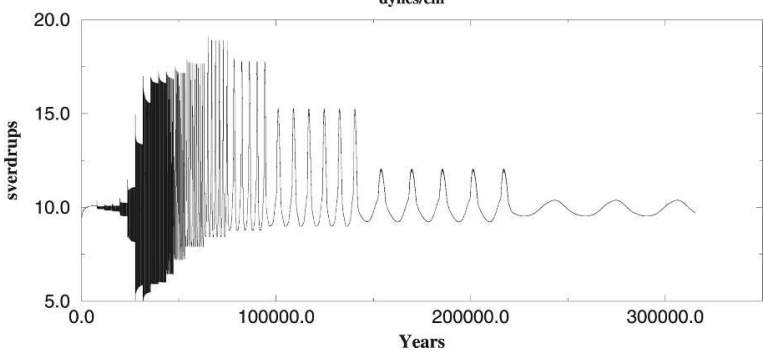

FIG. 6. (a) Wind stress distribution for expt D1 after Weaver and Sarachik (1990). (b) Maximum overturning against time for expt D1. The diffusion is $1 \mathrm{~cm}^{2} \mathrm{~s}^{-1}$.

coldest water that then fills the deep ocean. Furthermore, the longer the forcing period is, the more time those cold waters have to fill the deep ocean before being removed by diffusive warming (see section 4).

As the period is increased the amplitude of the oscillations increases slowly, until, for the 32000 -yr forcing, it reaches an amplitude of $2.5^{\circ} \mathrm{C}$. The bottom temperature now closely follows the behavior of the forcing temperature although its amplitude is still only one-half that of the forcing temperature. It is clear that the forcing signal now reaches all the way down to the bottom of the basin.

We also observe that the bottom temperature signal displays two dominant components. One component, the narrow trough, dominates the periods above 8 and below 1000 yr (Fig. 8). By this, we mean that the amplitude of the narrow trough accounts for most of the amplitude of the oscillations. The other component, the peak, is clearly dominant for periods of $2000 \mathrm{yr}$ and above. The two components suggest that the response of the system is the result of its adjustments to the forcing through two processes, each requiring a certain time scale to become efficient. One of these processes has an adjustment time of decades, and the other has an adjustment time in the millennial time band. The response of the system to a specific forcing period is a combination of the adjustment of the basin to the forcing through those two mechanisms at that specific forcing period (see sections 4 and 5).

\section{c. Phase lag}

In Fig. 9, we can see the evolution of the phase lag between the forcing temperature at $60^{\circ} \mathrm{N}$ (the temperature to which the sea surface temperature is being re- 
8 Years

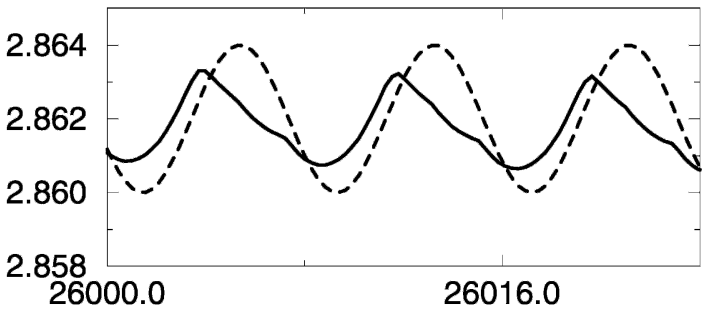

500 Years

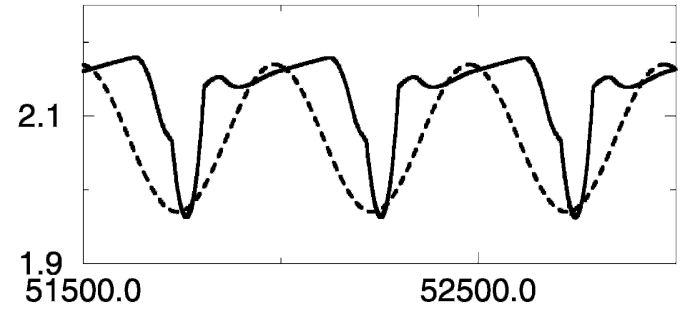

2000 Years

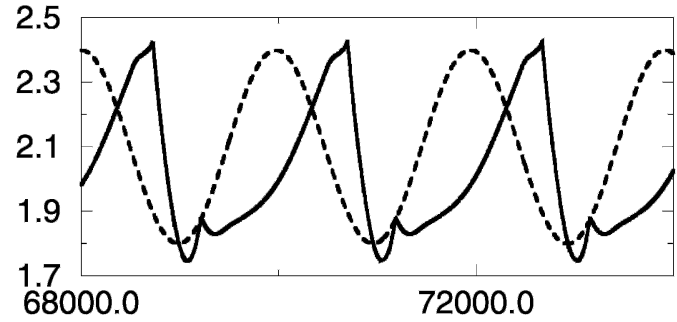

250 Years

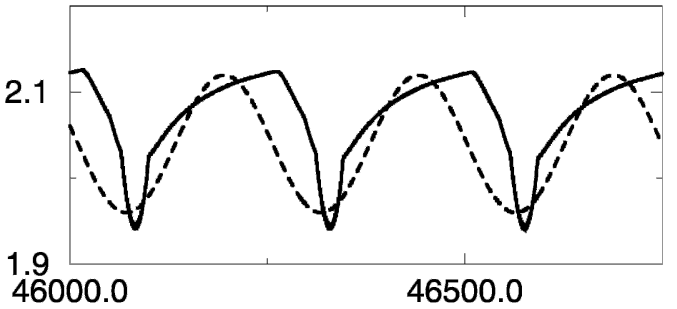

1000 Years

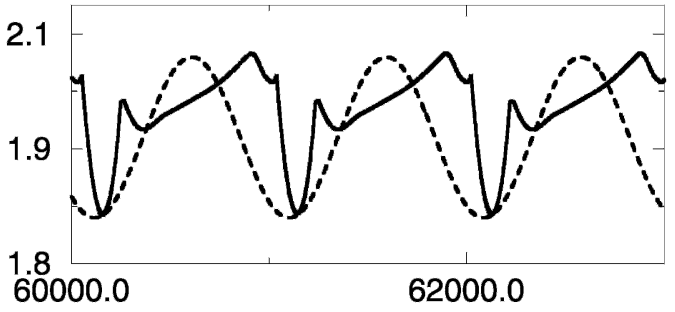

8000 Years

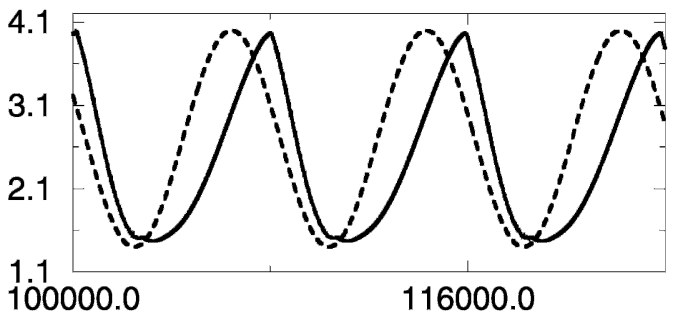

FIG. 7. Evolution of the minimum bottom temperature (solid) and the forcing temperature (dashed) during expt R1 over six different periods: 8, 250, 500, 1000, 2000, and $32000 \mathrm{yr}$. The forcing temperature has been scaled down to the bottom temperature range. As a consequence, no absolute values for the forcing temperature can be inferred from those plots. The forcing temperature is the restoring temperature of the northernmost $\left(60^{\circ}\right)$ latitude. Thus, when the forcing temperature is at a maximum, the north-south temperature gradient is at a minimum.

stored) and the response of the meridional overturning. For the very long forcing periods, the two signals are slightly out of phase. As the forcing period decreases, the lag between the forcing temperature and the response increases: for a forcing period of $4 \mathrm{yr}$, the lag is one full period (a lag of 0 ). This result means that in our model the minimum temperature gradient, and thus the maximum forcing temperature, leads to the maximum overturning, and vice versa, which is consistent with the results from the asymptotic runs. This figure also clearly demonstrates that the system is far more complex than a forced oscillator, because, for the resonance-like period of $2000 \mathrm{yr}$, the lag is clearly not $\pi / 2$, as it would be in a forced oscillator, but is $\pi$ (see also section 6 on the velocities).

We also observe that the nonlinearity of the response varies with the forcing. For small periods the response is quasi-sinusoidal, whereas for a forcing period of 2000 $\mathrm{yr}$ the response is highly nonlinear, with a very sharp peak and a longer trough. As the forcing period continues to increase, the peak becomes less pronounced and the response becomes more linear again.
To understand how the phase lag is set up, it is necessary to look at other quantities. In Fig. 10, we see the evolution of the convection index, the overturning, and the surface-to-bottom temperature difference. The convection index is an average over the sampling period of the number of cells in the model that undergo convective mixing. The surface-to-bottom temperature difference is obtained by subtracting the minimum bottom temperature from the minimum surface temperature.

We have two different types of behavior in the system: one for periods greater and another for periods smaller than 8 yr. For the forcing periods greater than $8 \mathrm{yr}$, the response of the overturning is almost perfectly in phase with the convection in the high latitudes. An increase in the strength of the convection index is followed by an increase in the strength of the overturning. As the period increases, the convection index plateaus for a longer time and the decrease in the strength of the overturning goes from lagging slightly the convection decrease to preceding it. For forcing periods below $8 \mathrm{yr}$, the convection index and the overturning are out of phase. 


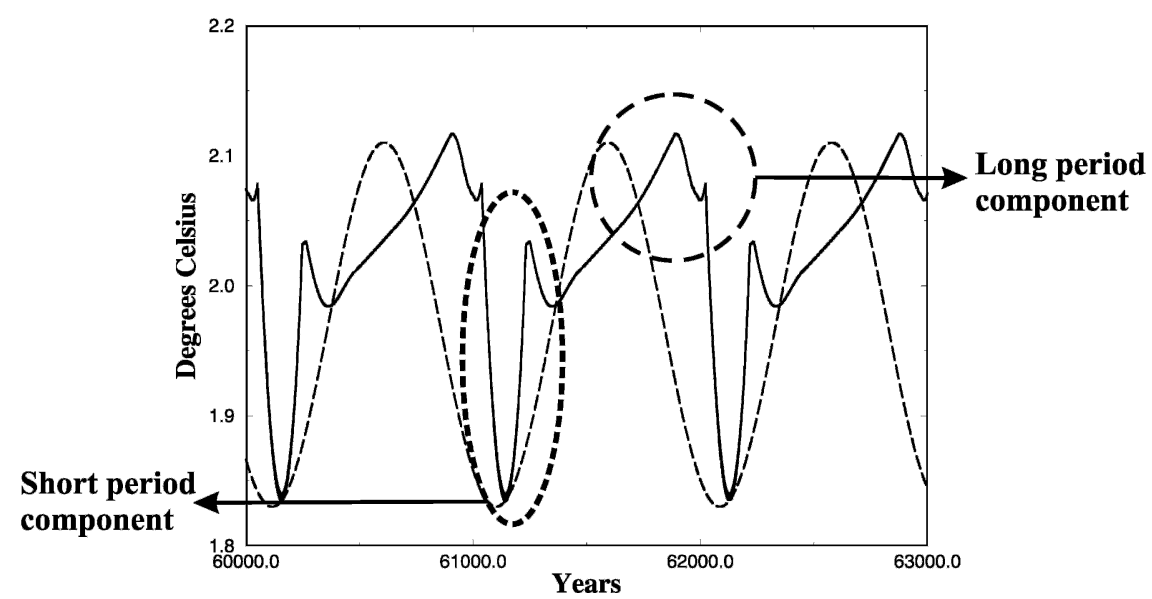

FIG. 8. Evolution of the minimum bottom temperature (solid line) and the forcing temperature (dashed line) during expt R1 over the 1000-yr forcing. This figure shows the two components of the bottom temperature signal.

The convection is well known for its abrupt changes once threshold values are reached (i.e., large convective areas are either switched "on" or "off"; Lenderink and Haarsma 1994). This effect explains why the convection index does not just follow the forcing and why it exhibits steplike increases and plateaus. The latter occur when all of the cells in an area that can undergo convection are already convecting. For additional deeper cells to convect (i.e., for the convection index to increase), a substantial amount of water must become unstable. In a similar way, if a deep cell is convecting, it must undergo a substantial cooling to become stable. Once it reaches that threshold value, it will stop convecting.

Figure 10 shows that it is the difference between the surface and the bottom temperatures that determines the amount of convection that takes place. The maximum convection occurs when the minimum surface temperature is smaller than the minimum bottom temperature. It is therefore the surface temperature signal and how it penetrates in the deeper ocean that determines the phase behavior between the forcing and the response. The surface temperature signal is itself the result of the effect of the forcing and the various processes that occur in the ocean, such as convection, diffusion, and advection (see section 4).

The response-that is, the strength of the overturning-clearly has a negative feedback on the surface ocean temperature: the stronger the overturning is, the stronger the western boundary current is and the more warm water is carried northward to the convection areas. Furthermore, the stronger the convection is, the smaller is the surface-to-depth temperature gradient. As for diffusion, what matters is not only how deep the forcing signal penetrates but also with what amplitude. All of this suggests that diffusion has a particular role to play in the response mechanism of the ocean basin and needs be studied further. Its behavior will be examined in detail in section 4 .

\section{Diffusion}

To obtain a deeper understanding of what happens as the period is increased, the behavior of the system for four forcing periods in R1 is analyzed: one small period (8 yr), one very long period (32000 yr), and two periods between those bounds (250 and $2000 \mathrm{yr}$ ). The 2000-yr period is also important because it corresponds to the maximum range in the overturning. Figure 11 shows the evolution of temperature and the meridional overturning at $52^{\circ} \mathrm{N}$ on the western side of the basin over one period of the forcing. For all of the periods examined, the surface temperature displays a warm bias when compared with the forcing profile, resulting from the advection of warm water northward by the boundary currents and the effect of convection.

For the very short periods the forcing signal does not penetrate below $1000 \mathrm{~m}$ in the temperature field. As the forcing period increases, the forcing signal penetrates deeper and deeper, although the ocean remains fairly stratified. The amount of stratification is, however, clearly reduced in the 32000 -yr forcing case. The surface temperature variation increases in amplitude as the forcing period increases, indicating that a greater amplitude of the forcing signal is captured by the surface ocean as the rate of change in the forcing decreases.

For periods of 250 and $2000 \mathrm{yr}$, the warming at depth is slow and occurs while the overturning and the convective mixing are at their minimum. The cooling of the waters on the other hand, occurs at the same time as the maximum overturning and is particularly fast, relative to the warming, for the 2000 -yr period. For the $32000-$ yr period, the cooling and the warming have almost the 
4 Years

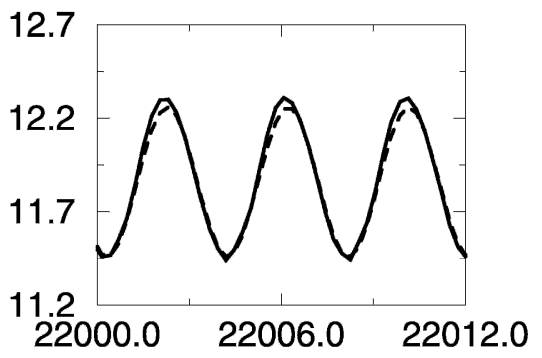

60 Years

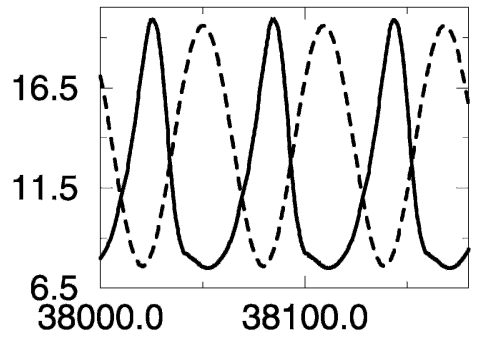

2000 Years

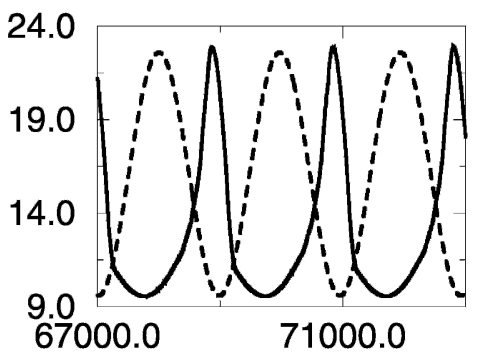

8 Years

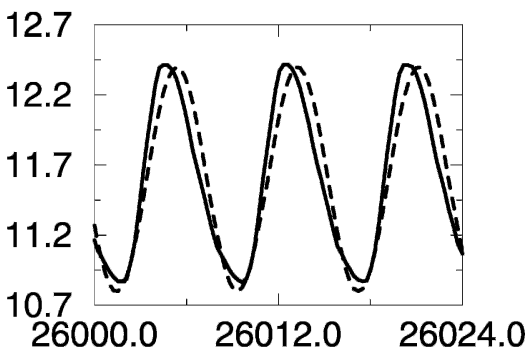

250 Years

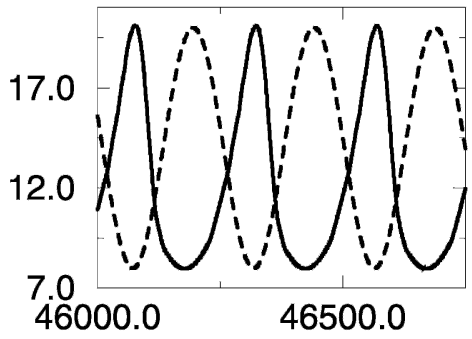

8000 Years

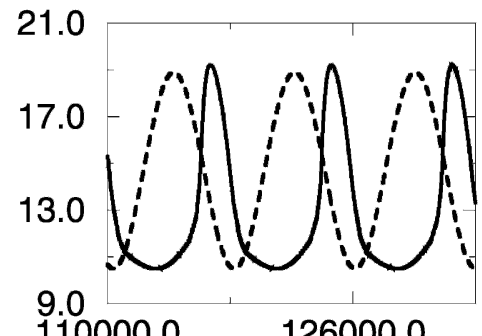

30 Years

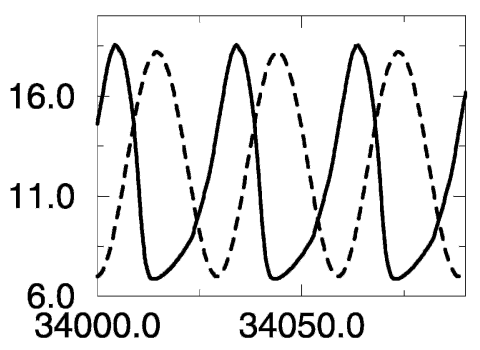

1000 Years

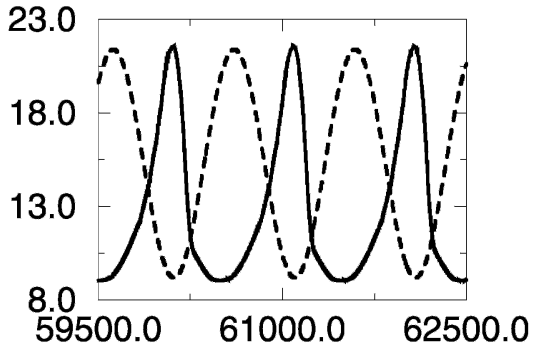

32000 Years

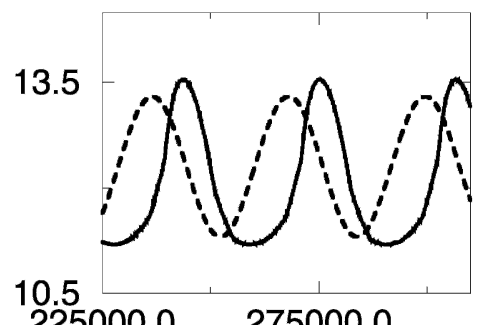

FIG. 9. Forcing temperature (dashed line) and overturning response (solid) in expt R1 for nine forcing periods. The forcing temperature has been scaled up to the overturning, and, as a result, no absolute value can be inferred. The forcing temperature is the restoring temperature of the northernmost $\left(60^{\circ}\right)$ latitude. Thus, when the forcing temperature is at a maximum, the north-south temperature gradient is at a minimum.

same rate. This contrast between the rates of warming and cooling has already been discussed by Stouffer (2004), although the experiments presented here suggest that the strength of this contrast depends greatly on the forcing period. Last, whereas for the short period (i.e., $250 \mathrm{yr}$ ), the minimum temperature at depth occurs at almost the same time as the maximum surface temperature is reached, with increased forcing period this antiphase behavior is diminished and for $32000 \mathrm{yr}$ the minimum deep temperature occurs at the same time as the minimum surface temperature.

The overturning streamfunction contour lines shows that it first strengthens and deepens from a forcing period of $8 \mathrm{yr}$ to a period of $2000 \mathrm{yr}$ before shoaling and weakening for a forcing period of $32000 \mathrm{yr}$.

Diffusion affects the system in two significant ways: 1) by controlling how much of the forcing signal the surface ocean will capture and 2) by determining how deep this captured signal will reach. The importance of the surface ocean in its ability to capture the forcing signal has already been suggested by Hasumi and Suginohara (1998). For small periods (below $250 \mathrm{yr}$ or so), the diffusion cannot keep pace with the changes in the forcing and thus only a small portion of the signal is captured by the surface ocean. Because the oscillation in the SST is so fast, the diffusion cannot transmit the forcing signal to the deep ocean; as a result, the amplitude of the deep ocean temperature oscillations is very small. As the period increases, more and more of the forcing signal is captured and transmitted to the deep ocean. Hence, for the forcing of $32000 \mathrm{yr}$, the warming and cooling are almost synchronous throughout the depth of the ocean. The depth to which the forcing signal penetrates, even for the small forcing periods, provides an explanation as to why the inclusion of wind in experiment D1 does not qualitatively alter the behavior of the system. Indeed, we see in Fig. 11a that the forcing signal has a distinct signature up to a depth of $500 \mathrm{~m}$, which is deeper than the average wind mixed layer.

The maximum overturning occurs when enough of 
8 Years

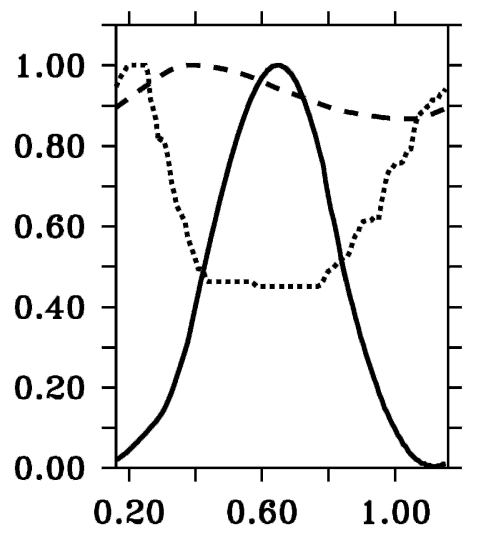

Temperature difference
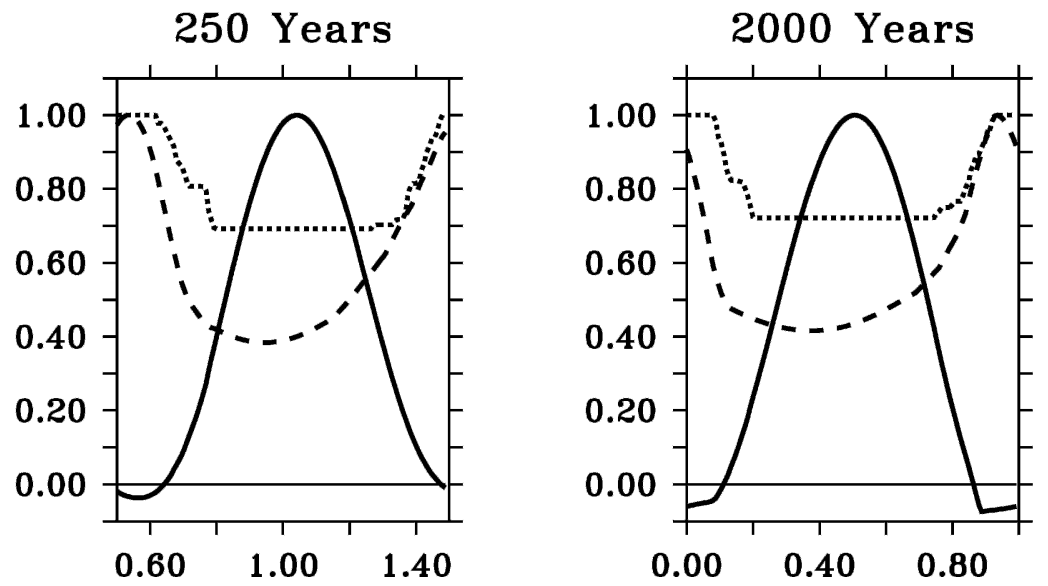

60 Years

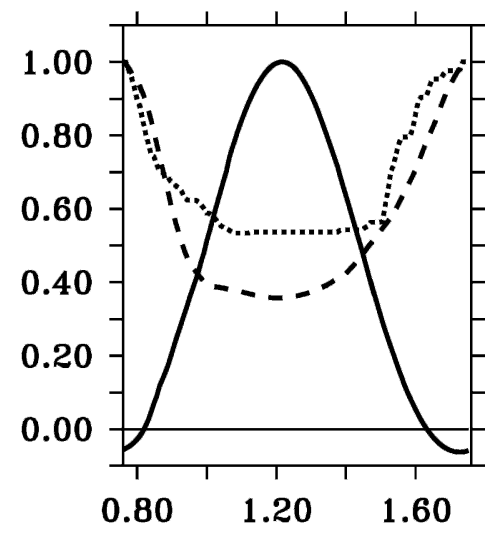

- Maximum Overturning

-.---. Convection Index

FIG. 10. Evolution over one period of the convection (dotted line), the maximum overturning (dashed line), and the surface-tobottom maximum temperature difference (solid line) for six forcing periods. All quantities have been normalized. The convection index is obtained by averaging (over a sampling period) the number of cells that undergo convection.

the forcing signal is captured to create buoyancy instabilities, which the diffusion is not efficient enough to remove. This creates convective mixing, which leads to an increase in the overturning. This allows for the fast removal of the instabilities and a rapid cooling of the ocean as is clearly shown in Fig. 11c where the warming of the deep ocean is slow and the cooling is fast whereas the surface ocean cooling and warming have the same rate. Following the cooling, the warming of the surface ocean leads to the creation of a highly stratified ocean, which is very stable. This condition explains why the trough in the overturning increases relative to the peak as the forcing period increases (Figs. 9 and 10). The fast cooling and slow warming also explain why the average bottom temperature increases for forcing periods of $1000 \mathrm{yr}$ or more. As the forcing period increases beyond the maximum overturning, the cooling, because of a combination of diffusion and convection, has reached a maximum efficiency. However, the warming of the deep ocean becomes increasingly more efficient as diffusion has more time to have an effect (Fig. 7). Thus, the absolute minimum bottom temperature remains constant for periods of more than $1000 \mathrm{yr}$ but the absolute maximum increases, leading to an increase of the average bottom temperature.

If we increase the value of the vertical diffusivity, we affect the system's capacity to capture the forcing signal and its response to it. This explains why the "resonance" shifts to the smaller periods when we increase the value of the vertical diffusivity: more of the signal is captured for the smaller forcing periods and the ocean is more capable of responding to it through diffusion alone. Note that what we see in the response of the overturning is a combination of the adjustments to the forcing through the two processes. The observed resonance-like signal (i.e., when the greatest amplitude oc- 
A Period of 8 years

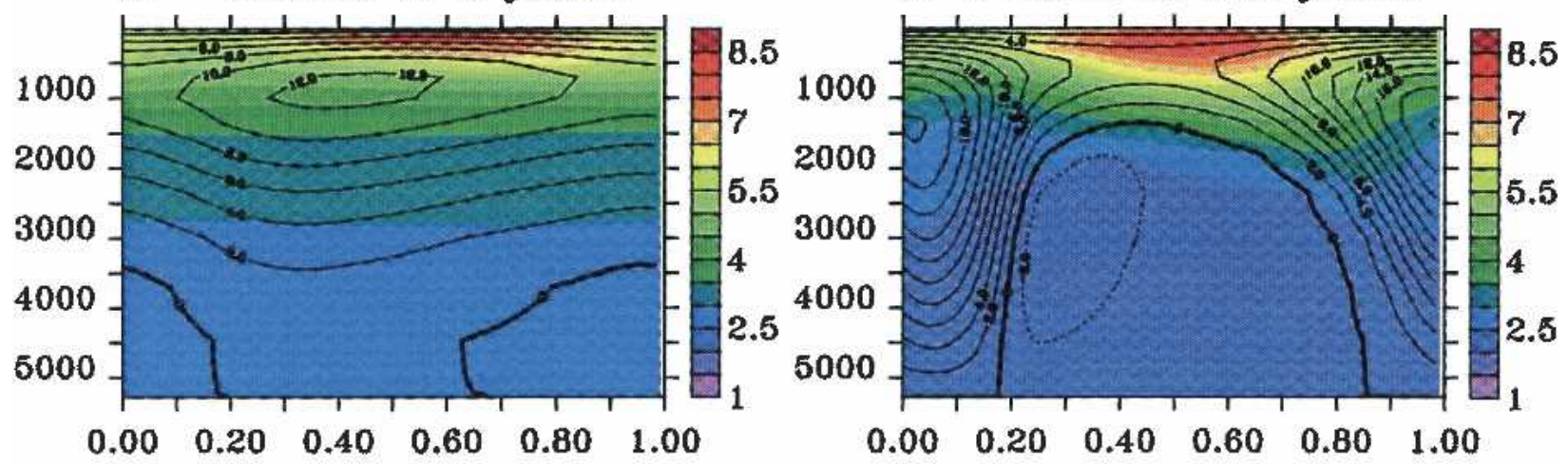

Black Contours: Meridional Stream Function (Sverdrups)
Colour Scale: Potential Temperature (Degrees Celsius)

C Period of 2000 years

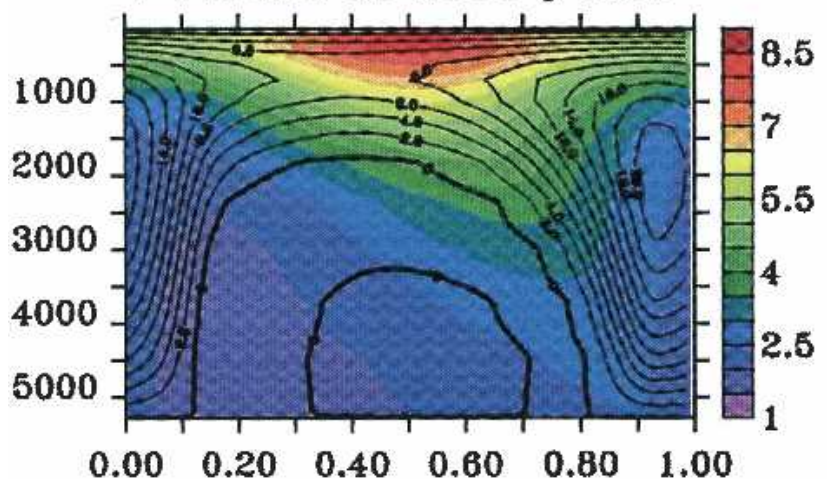

D Period of 32000 years

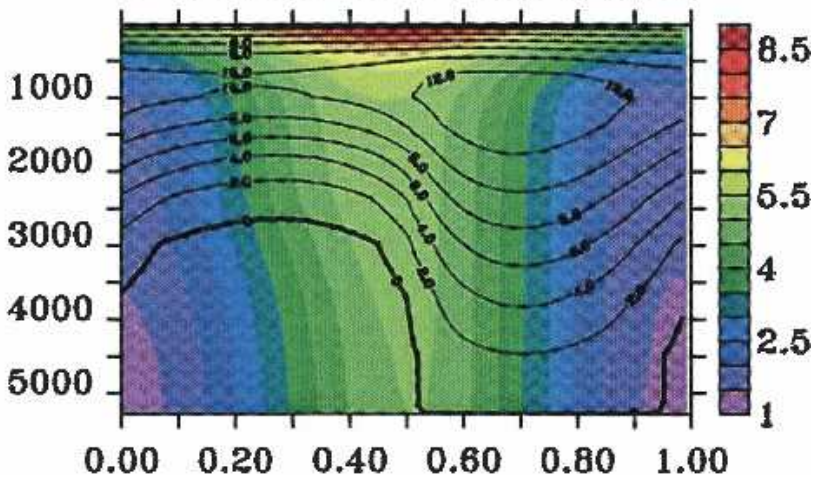

FIG. 11. Evolution of the temperature (color shading) and meridional streamfunction (contours) over the four forcing periods: (a) 8, (b) 250 , (c) 2000, and (d) 32000 yr. The sampling period is set at 1/125 of the forcing period. The $x$ axis shows the normalized period.

curs) results from the interaction of those two responses. This effect is why increasing the diffusion shifts the main resonance signal so much toward the smaller periods.

Increasing the vertical diffusivity also alters the tail end of the curves displaying maximum overturning versus time (Figs. 3, 4, and 5). As the diffusion increases, for the long periods, the response of the system becomes more and more linear. This is also evident for a fixed diffusion and variable forcing periods (Fig. 8): as the forcing period increases past the maximum response in the overturning (2000 yr for R1), the nonlinearity in the response becomes less pronounced. This decrease in nonlinearity is because as diffusion becomes the dominant mechanism (either because it is increased or because it has more time to have an effect) the ocean basin has to rely less and less on the other mechanisms (convection and advection) to adjust to the forcing. Furthermore, the ocean becomes less and less stratified, and thus less stable (Fig. 11d). As a result, the trough in the maximum overturning curve becomes less pronounced because the stratification is easier to break down and so the response becomes more linear. The linearity of the response of the ocean basin is therefore dependent on the forcing period and the value of the vertical diffusion.

To summarize, the ocean basin adjusts to the effect of diffusion in two ways: 1) in the way the forcing signal is captured in the surface ocean and 2) in the way in which this captured signal is transmitted to the deep ocean.

\section{Basin width}

We still have to find an explanation for the sudden increase in response amplitude as the forcing period increases from 8 to $15 \mathrm{yr}$. A plausible hypothesis suggests that the cross-basin travel time of baroclinic Rossby waves plays a role. To test this hypothesis, we set up experiment W1 to be identical to R1 in all but the basin width, which is 2 times that of $\mathrm{R} 1$, that is, $120^{\circ}$ of longitude. Once again, the system is spun up for 8000 $\mathrm{yr}$ and then is submitted to the same thermal forcing as R1. 


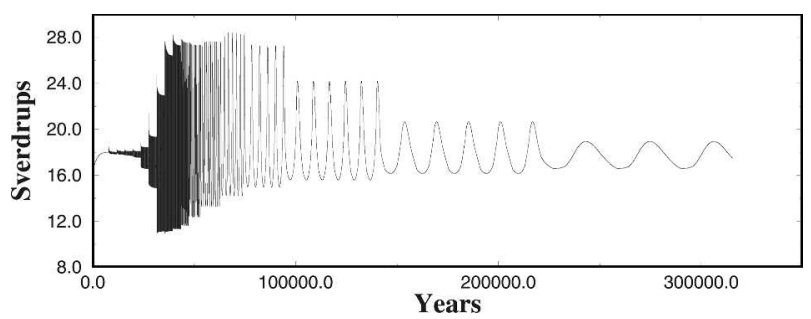

FIG. 12. Maximum meridional overturning streamfunction for expt W1. The vertical diffusion is $1 \mathrm{~cm}^{2} \mathrm{~s}^{-1}$, and the basin is $120^{\circ}$ wide. The model is run for 17 forcing periods and for each until a cyclostationary state has been achieved.

Figure 12 shows the resulting behavior of the maximum overturning. The average overturning is stronger, but this result is easily accounted for by the increase in basin width, implying stronger zonally integrated vertical diffusive fluxes and resulting in stronger vertical advection (Marotzke and Klinger 2000). In broad terms, however, the behavior is similar to that of the maximum overturning for R1. There is one important difference. The position of the jump in amplitude now occurs between a forcing period of $15 \mathrm{yr}$ and a forcing period of $30 \mathrm{yr}$. Furthermore, in a fashion similar to R1, the absolute minimum in the overturning is found just after the jump, for the forcing period of $30 \mathrm{yr}$. This pattern is consistent with an important role of Rossby waves.

If we now examine the temperature anomaly in R1 on either side of the jump, for the forcing periods of 8 and $60 \mathrm{yr}$, at midlatitudes $\left(30^{\circ} \mathrm{N}\right)$ and just below the thermocline (800-m depth), a westward-propagating signal is visible (Fig. 13). For $8 \mathrm{yr}$, we see that there is some propagation of a signal from east to west but that it does not cross the whole basin. Furthermore, the temperature trend is not uniform zonally. We have instances of warming in the east while the west is cooling, and vice versa. For $60 \mathrm{yr}$, the picture is different. The

\section{A Period of 8 years}

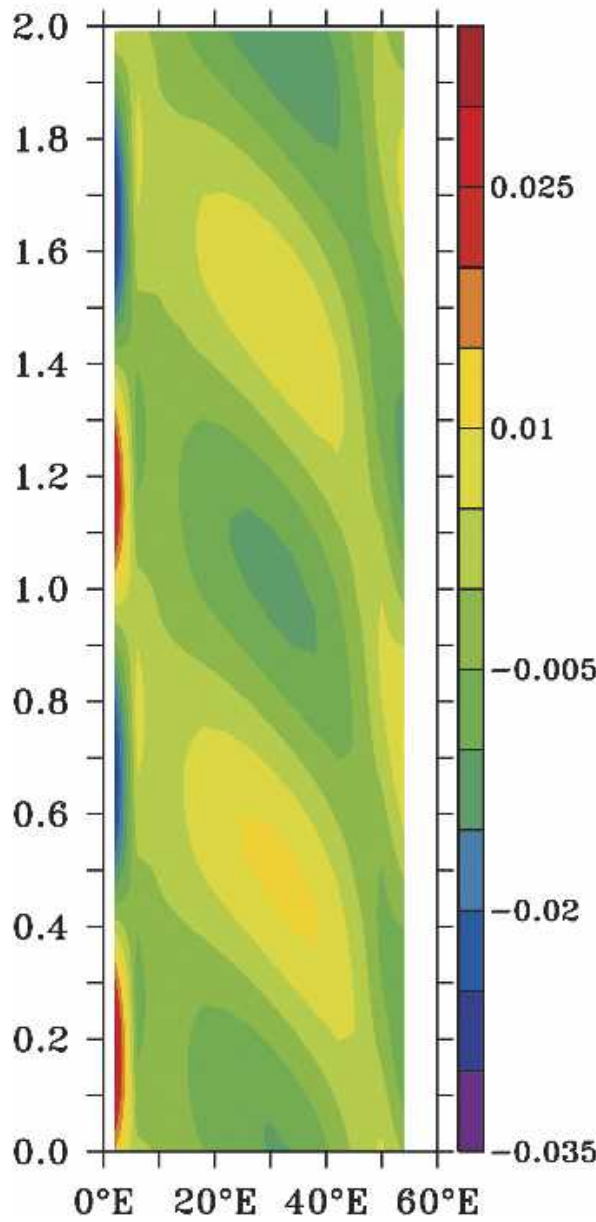

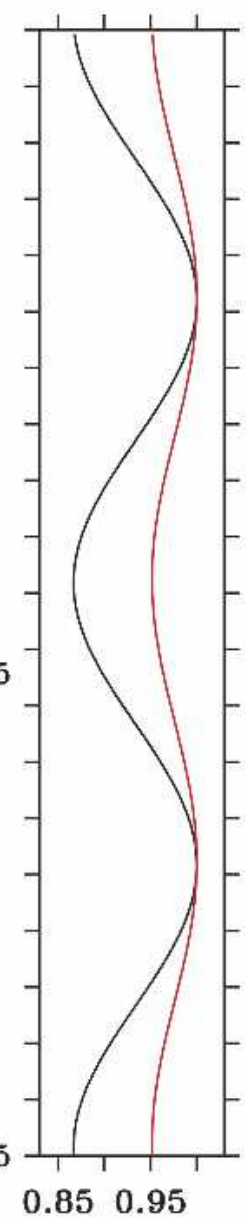

B Period of 60 years

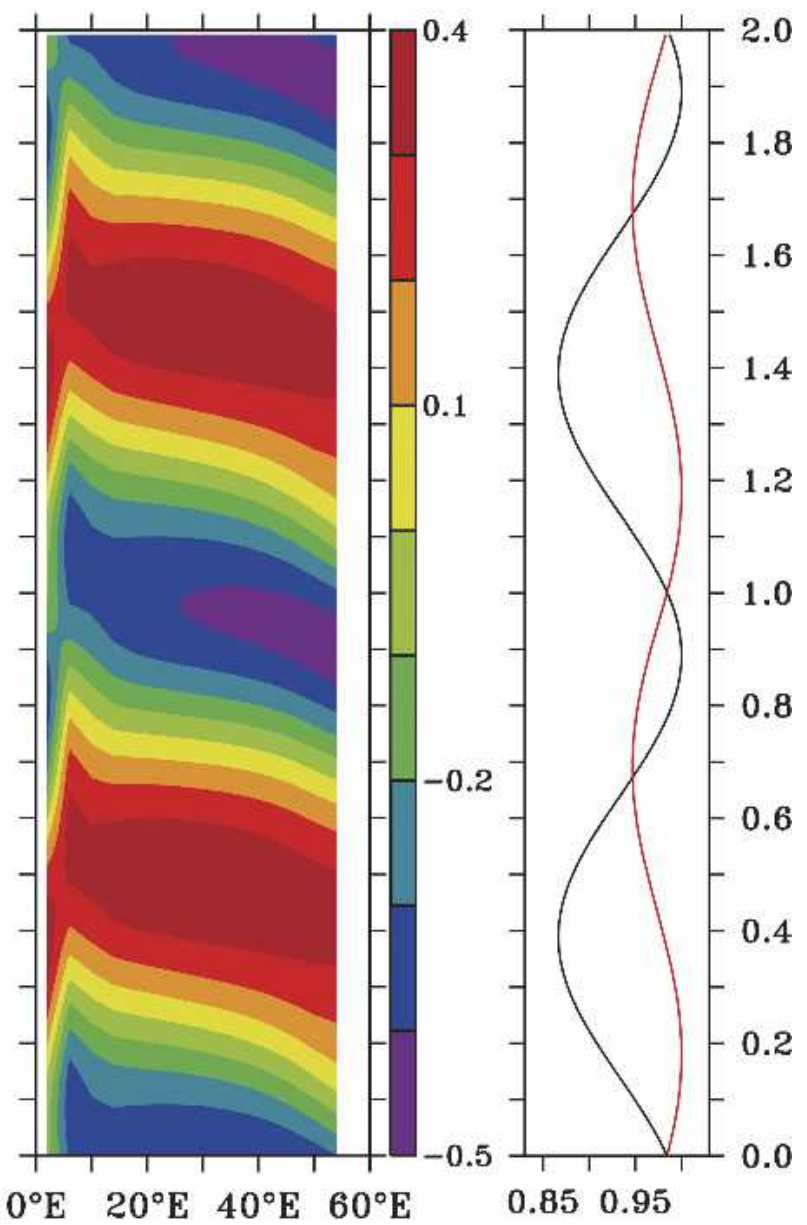

FIG. 13. Hovmoeller plots of the temperature anomaly at $800-\mathrm{m}$ depth at $30^{\circ} \mathrm{N}$, the normalized average surface temperature (red line), and the normalized restoring temperature (black line) for forcing periods of (a) 8 and (b) $60 \mathrm{yr}$. The color contours are in degrees Celsius, and the $y$ axis shows two normalized periods. 
warming and cooling trends are uniform across the whole basin: when the east is warming the west is also warming. Furthermore, the amplitude of the warming is almost an order of magnitude greater than for the forcing period of $8 \mathrm{yr}$.

The slope of the isotherms for the period of $60 \mathrm{yr}$ indicates that the anomaly crosses the whole basin in about $5 \mathrm{yr}$. The shorter period of the jump in the response of the overturning in R1, as compared with $\mathrm{W} 1$, is therefore set by the basin width. Doubling the basin width doubles the period at which the maximum increase in the amplitude occurs. The analysis of Fig. 13 suggests that the westward propagation of the temperature anomaly results from the activity of a Rossby wave. Indeed, for the 8-yr forcing period the anomaly takes roughly $3.9 \mathrm{yr}$ to cross the basin from east to west, whereas for the 60 -yr forcing period it crosses the basin in roughly $4.2 \mathrm{yr}$.

A very simple two-layer model of the ocean basin with a thermocline at $800 \mathrm{~m}$ and an average temperature of $14^{\circ} \mathrm{C}$ above the thermocline and of $4^{\circ} \mathrm{C}$ below the thermocline yields a gravity wave speed of 3.4 $\mathrm{m} \mathrm{s}^{-1}$, implying a midlatitude $\left(30^{\circ} \mathrm{N}\right)$ wave speed of long Rossby waves of $0.043 \mathrm{~m} \mathrm{~s}^{-1}$. Such a wave takes 4.2 yr to cross a $60^{\circ}$-wide basin, which means that for an anomaly to cross the basin in an uninterrupted fashion the warming or cooling period must be greater than 4.2 yr. This result corresponds to a forcing period of $8.4 \mathrm{yr}$.

The velocities have been calculated here for Rossby waves at $30^{\circ} \mathrm{N}$. As discussed by Cessi and Louazel (2001), it is the slowest Rossby waves that determine the basin adjustment time. We can therefore theorize that the northernmost Rossby waves are those that determine the adjustment time. However, in the high northern latitudes, the signal generated by those waves is hard to pick out because these latitudes are the location of other processes such as convection.

For the $8 \mathrm{yr}$ forcing period, the cooling and warming of the anomaly (Fig. 13a) are exactly in phase with the behavior of the surface temperature. In other words, we have an anomaly traveling across the basin and it is warmed and cooled by the forcing. The amplitude of the anomaly is very weak, about a 50th of what it is for the 60 -yr period (an amplitude $0.03^{\circ} \mathrm{C}$ vs an amplitude of $0.9^{\circ} \mathrm{C}$ ). For forcing periods above $15 \mathrm{yr}$, the Rossby wave signal swamps the direct effect of the surface forcing and therefore we do not see any evidence of the direct effect of the surface cooling and warming (Fig. 13b). So, in effect, we have an anomaly that is built up by the activity of Rossby waves. If the forcing is fast, the anomaly has a very weak amplitude and is still sensitive to what happens at the surface. If the forcing is slow, the anomaly's amplitude is much greater and the surface forcing has no direct visible effect on it. Furthermore, because the overturning is that much more stronger, the surface temperature does not follow so closely the forcing because we have stronger advective processes taking place.
The mechanism generating those Rossby waves is similar to that described by Cessi and Louazel (2001) and Johnson and Marshall (2002) in that we observe the propagation of boundary-trapped waves along the western boundary, which when they reach the southernmost boundary travel eastward along it and then north along the eastern boundary. The northward propagation along the eastern boundary of these waves, created by the arrival of the equatorial boundarytrapped waves as well as the oscillations in the surface forcing, generate the long Rossby waves, which propagate westward.

The boundary-trapped waves propagating along the western boundary are readily visible in our model. They take roughly $3 \mathrm{yr}$ to travel from $60^{\circ} \mathrm{N}$ to the equator (not shown). This is about one-tenth as fast as the expected propagation time of Kelvin wave in a model with a $4^{\circ}$ resolution (Hsieh et al. 1983). Similar slowly propagating waves were also reported by Marotzke and Klinger (2000). These waves have all the features of Kelvin waves but propagate much more slowly.

These Kelvin-like waves can also be followed along the equator for the short-period forcing. Their crossing time is on the order of a year, and the eastward propagation is clearly visible. For the longer periods (i.e., 60 $\mathrm{yr}$ ), their signature is swamped by that of the long Rossby waves, and, as a result, only a westwardpropagating signal is visible. Because they are closer to the equator, these Rossby waves should travel faster than those farther north. Indeed, when we compare their speed with that of the waves in Fig. 12b, the former cross the basin in about $3.4 \mathrm{yr}$ while the latter take roughly 3.9 yr to cross it.

This analysis suggests that the basin possesses a characteristic time scale that is determined by the speed of the slowest Rossby wave. If the period of the forcing is greater than 2 times that time scale, the Rossby waves build up a temperature anomaly, which crosses the basin. This anomaly increases the amplitude of the eastwest pressure gradient, which in turn leads to an increase in the amplitude of the overturning. The greater the forcing period is, the more efficient this adjustment becomes. As a result, the amplitude of the anomaly increases as the Rossby waves have more time to build up the positive and negative anomalies. This process is one of the ways through which the basin adjusts to the changes in the forcing. In our experiments, however, as the forcing period exceeds $1000 \mathrm{yr}$, the adjustment to the forcing through the effects of diffusion swamps the effect of the adjustment to the forcing through the effect of Rossby waves (Fig. 7).

If the period of the forcing is less than 2 times the characteristic time scale, the east-west pressure gradient is unaffected, because the wave signal is severely damped by the effect of the changing surface forcing. In this instance, because the anomaly does not reach the western side of the basin, or rather it reaches it but in an extremely damped form, there is no increase in the 

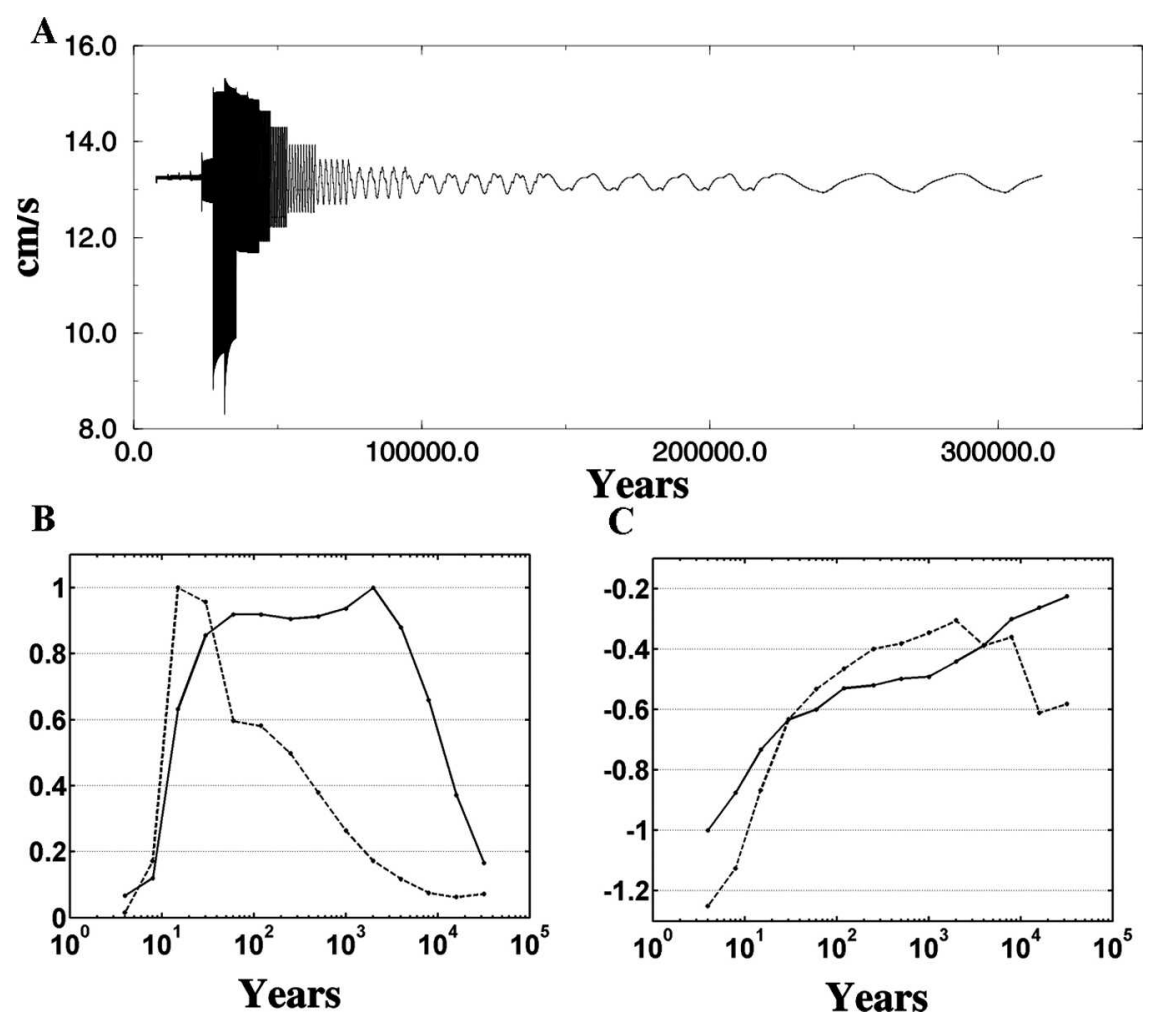

FIG. 14. (a) Maximum $V$ velocity against time for expt R1. The diffusion is $1 \mathrm{~cm}^{2} \mathrm{~s}^{-1}$. The model is run for 17 forcing periods and for each until cycloequilibrium has been achieved. (b) Normalized amplitude of the maximum overturning (solid line) and maximum $V$ velocity (dashed line) in expt R1 against the forcing period. (c) Phase shift in fraction of a period between the forcing and the maximum overturning (solid line) and maximum $V$ velocity (dashed line) in expt R1 against the forcing period.

amplitude of the overturning. Furthermore, because this anomaly travels more slowly than the change in the surface forcing, if it is created during the warming phase, it will reach the western side of the basin during the cooling phase and will thus interact destructively with the cooling that is now taking place. For long enough forcing periods, the Rossby wave signal interferes constructively with the signal migrating southward along the western boundary and much larger amplitudes are reached. All of this suggests that baroclinic wave propagation plays an important role in the adjustment of the ocean basin to external oscillations, in contrast to the conclusion of Eden and Greatbatch (2003).

It must be noted that our model has a very coarse resolution and uses an Arakawa B grid. Furthermore, the time stepping is asynchronous. As a result, the wave processes, although present, are not well resolved. As suggested by Döscher et al. (1994), this fact means that the model might be overestimating the response time of the ocean to changes in the surface forcing. The implications for our study are that the jump (e.g., the sudden increase in the amplitude of the overturning oscillations) might be occurring for a greater forcing period than in a fine-resolution model and that, because of the absence of very fast waves, the amplitude of the oscillations of the overturning for very small forcing periods $(0.5,1$, and $2 \mathrm{yr})$ might be underestimated.

There is the possibility that the internal variability of the model could affect the response to periodic forcing, particularly because it is usually of the same order as the time scale set by the basin width (Colin de Verdiere and Huck 1999). Indeed, the internal variability, visible during run F1 with constant fluxes, has a period of 22.7 yr (not shown). Although this value is higher than the period for which the jump is observed, it is sufficiently close to the time scale set by the adjustment of the basin to the activity of Rossby waves to possibly contaminate the signal. However, the response in the amplitude of the maximum overturning shows no particular sensitivity to the internal oscillation time scale, even when a forcing period of exactly $22.7 \mathrm{yr}$ is used. This fact is probably because the restoring is sufficiently strong to damp out completely the internal oscillations.

\section{Boundary current velocities}

Figure 14a shows the evolution of the maximum meridional velocity $V$ against time during experiment R1. 
As for the overturning, $V$ exhibits a resonance- like structure as well as the jump in amplitude. The curves, however, clearly show that the response of $V$ is far more nonlinear than that of the overturning. This result is particularly clear for the long periods, $4000 \mathrm{yr}$ and above. As illustrated in Fig. 14b, the maximum amplitude occurs for a period that is smaller than that for the maximum overturning - that is, $30 \mathrm{yr}$ against $2000 \mathrm{yr}$ for the maximum overturning. This is surprising and suggests that the maximum overturning behaves differently than the western boundary current where the maximum value for $V$ is found.

Furthermore, as is indicated in Fig. 14c, the phase shift between the maximum overturning and the maximum $V$ varies with the forcing period. In other words, within an oscillation, both quantities reach a maximum at a different time in the forcing cycle. This condition means that in an oscillatory system care is needed when one wants to infer the strength of the MOC and the northward heat transport from velocity measurements in the western boundary current, as has been done in some paleostudies (Lynch-Stieglitz et al. 1999).

Figures $14 \mathrm{~b}$ and $14 \mathrm{c}$ clearly illustrate the complexity of the system, which cannot really be compared to a forced oscillator. Indeed, neither the velocity nor the overturning reaches a maximum amplitude when their respective phase shifts with the forcing are one-quarter of a period $(\pi / 2)$.

\section{Conclusions}

Even a very simple model ocean basin forced with highly idealized variable buoyancy forcing responds in a very complex way. It exhibits a very strong response in the meridional overturning streamfunction, with large oscillations even for forcing periods on the order of Milankovitch cycles.

The amplitude of the oscillations presents a resonance-like behavior that stems from the existence of two adjustment time scales, one in the decadal band and one in the millennial band. The former is unaffected by changes in the vertical diffusivity or the introduction of simple topography or idealized wind forcing and is set by the propagation speed of Rossby waves across the basin. It consequently depends on the basin width. The latter is controlled by the diffusion: the greater the diffusion is, the smaller the period of the resonance is. The basin adjusts to changes in the forcing through those two processes.

The relationship between western boundary meridional velocities and the meridional overturning is complex. This finding suggests that there is no simple inference of overturning and heat transport from local inferred paleovelocities.

Acknowledgments. This work was financed by NERC through the COAPEC initiative. We are grateful for the constructive comments of the two anonymous reviewers.

\section{REFERENCES}

Brickman, D., W. Hyde, and D. G. Wright, 1999: Filtering of Milankovitch cycles by the thermohaline circulation. J. Climate, 12, 1644-1658.

Bryan, F., 1987: On the parameter sensitivity of primitive equation ocean general circulation models. J. Phys. Oceanogr., 17, 907-985.

Bryan, K., and M. Cox, 1967: A numerical investigation of the oceanic general circulation. Tellus, 19, 54-80.

Cessi, P., and S. Louazel, 2001: Decadal oceanic response to stochastic wind forcing. J. Phys. Oceanogr., 31, 3020-3029.

CGCM, 1999: Maps of the World Environments during the Last Two Climatic Extremes (CLIMEX). CGCM, 1 pp.

Colin de Verdiere, A., 1988: Buoyancy driven planetary flows. $J$. Mar. Res., 46, 215-265.

_ , and T. Huck, 1999: Baroclinic instability: An oceanic wavemaker for interdecadal variability. J. Phys. Oceanogr., 29, 893-910.

Delworth, T. L., and R. J. Greatbatch, 2000: Multidecadal thermohaline circulation variability driven by atmospheric surface flux forcing. J. Climate, 13, 1481-1495.

— , and M. E. Mann, 2000: Observed and simulated multidecadal variability in the Northern Hemisphere. Climate Dyn., 16, 661-676.

_, S. Manabe, and R. J. Stouffer, 1993: Interdecadal variations of the thermohaline circulation in a coupled oceanatmosphere model. J. Climate, 6, 1993-2011.

Döscher, R., C. W. Böning, and P. Herrmann, 1994: Response of circulation and heat transport in the North Atlantic to changes in thermohaline forcing in northern latitudes: A model study. J. Phys. Oceanogr., 24, 2303-2320.

Eden, C., and R. J. Greatbatch, 2003: A damped decadal oscillation in the North Atlantic climate system. J. Climate, 16, 4043-4060.

Gent, P. R., and J. C. McWilliams, 1990: Isopycnal mixing in ocean circulation models. J. Phys. Oceanogr., 20, 150-155.

Greatbatch, R. J., and K. A. Peterson, 1996: Interdecadal variability and oceanic thermohaline adjustment. J. Geophys. Res., 101, 20 467-20 482.

Griffies, S. M., 1998: The Gent-McWilliams skew flux. J. Phys. Oceanogr., 28, 831-841.

Hasumi, H., and N. Suginohara, 1998: Effects of the seasonal variation on forming the steady state of an atmosphere ocean coupled system. Climate Dyn., 14, 803-812.

Hsieh, W. W., M. K. Davey, and R. C. Wajsowicz, 1983: The free Kelvin wave in finite-difference numerical models. J. Phys. Oceanogr., 13, 1383-1397.

Huang, R. X., 1999: Mixing and energetics of the oceanic thermohaline circulation. J. Phys. Oceanogr., 29, 727-746.

Hurrell, J. W., Y. Kushnir, and M. Visbeck, 2001: Climate-The North Atlantic oscillation. Science, 291, 603.

Johnson, H. L., and D. P. Marshall, 2002: A theory for the surface Atlantic response to thermohaline variability. J. Phys. Oceanogr., 32, 1121-1132.

Kalnay, E., and Coauthors, 1996: The NCEP/NCAR 40-Year Reanalysis Project. Bull. Amer. Meteor. Soc., 77, 437-471.

Lenderink, G., and R. J. Haarsma, 1994: Variability and multiple equilibria of the thermohaline circulation associated with deep-water formation. J. Phys. Oceanogr., 24, 1480-1493.

Lynch-Stieglitz, J., W. B. Curry, and N. Slowey, 1999: A geostrophic transport estimate for the Florida Current from the oxygen isotope composition of benthic foraminifera. Paleoceanography, 14, 360-373.

Marotzke, J., 1990: Instabilities and multiple equilibria of the thermohaline circulation. Ph.D. thesis, Institut für Meereskunde, Kiel, Germany, 126 pp. 
—_, 1997: Boundary mixing and the dynamics of threedimensional thermohaline circulations. J. Phys. Oceanogr., 27, 1713-1728.

— , and B. A. Klinger, 2000: The dynamics of equatorially asymmetric thermohaline circulations. J. Phys. Oceanogr., 30, 955970.

Nilsson, J., and G. Walin, 2001: Freshwater forcing as a booster of thermohaline circulation. Tellus, 53A, 629-641.

—, G. Brostrom, and G. Walin, 2003: The thermohaline circulation and vertical mixing: Does weaker density stratification give stronger overturning? J. Phys. Oceanogr., 33, 2781-2795.

Park, Y.-G., and K. Bryan, 2000: Comparison of thermally driven circulations from a depth-coordinate model and an isopycnallayer model. Part I: Scaling-law sensitivity to vertical diffusivity. J. Phys. Oceanogr., 30, 590-605.

, and — 2001: Comparison of thermally driven circulations from a depth-coordinate model and an isopycnal-layer model. Part II: The difference and structure of the circulations. J. Phys. Oceanogr., 31, 2612-2624.

Ruddiman, W. F., N. J. Shackleton, and A. McIntyre, 1986: North Atlantic sea surface temperatures for the last 1.1 million years. North Atlantic Palaeoceanography, C. P. Summerhayes and N. J. Shackleton, Eds., Blackwell, 155-173.

Scott, J. R., 2000: The roles of mixing, geothermal heating and surface buoyancy forcing in ocean meridional overturning dynamics. Ph.D. thesis, Massachusetts Institute of Technology, 128 pp.

Stouffer, R. J., 2004: Time scales of climate response. J. Climate, 17, 209-217. te Raa, L. A., and H. A. Dijkstra, 2002: Instability of the thermohaline ocean circulation on interdecadal timescales. J. Phys. Oceanogr., 32, 138-160.

Visbeck, M., H. Cullen, G. Krahmann, and N. Naik, 1998: An ocean model's response to North Atlantic Oscillation-like wind forcing. Geophys. Res. Lett., 25, 4521-4524.

Weaver, A. J., and E. S. Sarachik, 1990: On the importance of vertical resolution in certain ocean general circulation models. J. Phys. Oceanogr., 20, 600-609.

—, and _ 1991: Evidence for decadal variability in an ocean general circulation model: An advective mechanism. Atmos.Ocean, 29, 197-231.

- J. Marotzke, P. F. Cummins, and E. S. Sarachik, 1993 Stability and variability of the thermohaline circulation. $J$. Phys. Oceanogr., 23, 39-60.

Webb, D. J., 1995: Development of the OCCAM global model for the Cray T3D. WOCE Rep. 125/95, WOCE International Project Office, 24 pp.

- 1996: An ocean model code for array processor computers. Comput. Geosci., 22, 569-578.

Winton, M., 1996: The role of horizontal boundaries in parameter sensitivity and decadal-scale variability of coarse-resolution ocean general circulation models. J. Phys. Oceanogr., 26, 289-304.

Zhang, J., R. W. Schmitt, and R. X. Huang, 1998: Sensitivity of the GFDL Modular Ocean Model to the parameterization of double-diffusive processes. J. Phys. Oceanogr., 28, 589-605. 